Check for updates

Cite this: RSC Adv., 2017, 7, 31696

Received 14th April 2017

Accepted 26th May 2017

DOI: 10.1039/c7ra04232a

rsc.li/rsc-advances

\section{Efficient organic-inorganic intumescent interfacial flame retardants to prepare flame retarded polypropylene with excellent performance}

\author{
Fei Qi, ${ }^{a}$ Mengqi Tang, ${ }^{a}$ Na Wang, ${ }^{a}$ Nian Liu, ${ }^{a}$ Xiaolang Chen, (DD *ac Zhibin Zhang, ${ }^{b}$ \\ Kun Zhang ${ }^{a}$ and Xiong Lu $^{a}$
}

In this article, an efficient and simple approach for the preparation of organic-inorganic intumescent interfacial flame retardants, aiming at enhancing the flame-retardant efficiency and interfacial adhesion between matrix and flame retardants was presented. The expandable graphite (EG) was functionalized by using a grafting process containing phosphorous, resulting in the formation of organic-inorganic intumescent flame retardants. Based on the successful grafting reaction, a series of flame-retardant polypropylene (PP) composites with different content of modified EG (MEG) were prepared and evaluated. With the incorporation of 30 wt\% of MEG into PP, the satisfactory UL-94 flame retardant grade ( $\mathrm{V}-\mathrm{O}$ ) and limiting oxygen index (LOI) as high as $25.3 \%$ were obtained. The residues of the PP/MEG composites were significantly increased with PP/EG and PP/EG/DOPO composites. Moreover, the residual char of PP/MEG composites is more compact and integrated. In addition, the formation of organic side chains on the MEG surface by the grafting reaction also contributed to an improvement in the interfacial compatibility, leading to an enhancement in mechanical properties of the composites compared with the PP composites filled with EG. The interfacial grafting flame retardants provided a novel way to prepare organic-inorganic intumescent flame retardants and the as-prepared flame retardants exhibited excellent flame retardant efficiency.

\section{Introduction}

Polypropylene (PP) is a polymer material which is widely used in various industries such as in chemical, petroleum and building. However, PP is flammable and will release CO, combustible gas and other toxic gases during combustion which are very harmful to human health and the environment. ${ }^{\mathbf{1 , 2}}$ Furthermore, the flammability of PP is a disadvantage in some applications industries where high flame retardancy is required, for example, in electrical applications, transportation sectors and daily necessities. ${ }^{3-7}$ Therefore, seeking desirable flame retardant for PP is quite necessary. At present, the main method is to mix flame retardant into the polymer directly. Over the past two decades, with the limitation of halogen-containing flame retardants and increasing requirements of high fire security for residential safety and environmental concerns, the main effort on flame retardants of PP has shifted to the development of halogen-free flame retardants. Considering the inherent

${ }^{a}$ Key Laboratory of Advanced Materials Technology Ministry of Education, School of Materials Science and Engineering, Southwest Jiaotong University, Chengdu 610031, China. E-mail: chenxl612@sina.com

${ }^{b}$ School of Life Science and Engineering, Southwest Jiaotong University, Chengdu 610031, China

${ }^{c}$ Sichuan Haoyuan Plastic Co., Ltd., Chengdu 611330, China flammability of PP and its application requirements, a suitable halogen-free flame retardant should be efficient enough in low additions to enhance flame-retardant performance and simultaneously to maintain the good mechanical and thermal properties of PP. ${ }^{8-12}$

As a newly emerged intumescent additive, expandable graphite (EG) is one of the halogen-free flame retardants, which has a special graphite intercalation compound where sulfuric acid $\left(\mathrm{H}_{2} \mathrm{SO}_{4}\right)$ is intercalated between the carbon layers. ${ }^{13-15}$ EG can exfoliate or expand along the $C$ axis of the crystal structure by about 100 times and forms a 'worm-like' structure with numerous ordered graphite flakes which can act as a protection layer of the polymer matrix to induce the heat and gas transfer during combustion. ${ }^{\mathbf{1 6 , 1 7}}$ However, it is usually observed that the incorporation of EG into polymer matrix not only reduces the compatibility between the matrix and the filler, but also the residual carbon layer is quite loose, which results in less protection to the inner matrix. Therefore, it is proposed that the phosphorus-containing flame retardant which can decompose into phosphoric acid during the high temperature can effectively solve this problem.

Phosphorus-containing flame retardants at high temperature can produce phosphate-carbon complexes which are thick and have high temperature resistance effect. Therefore, it can agglomerate the 'worm-like' carbon layer and form a physical 
barrier layer with excellent thermal stability property at high temperature. Phosphorus-containing flame retardants seem to offer a promising halogen-free method for the PP matrix and its composites in the future. Especially, 9,10-dihydro-9-oxa-10phosphaphenanthrene-10-oxide (DOPO) is one of the most important phosphorus-based flame retardants because of its excellent environmental compatibility. DOPO can act its role not only in the gas phase (via gas production), but also in the condensed phase (via char formation). With high reactivity, the $\mathrm{P}-\mathrm{H}$ group of DOPO can react with many functional groups such as epoxides, ${ }^{18-21}$ providing a novel way for preparing the organic-inorganic intumescent interfacial flame-retardants. However, it also has some negative impacts on thermal properties and compatibility between matrix and fillers. In order to graft DOPO onto the EG, the silane coupling agent with epoxide group named $\gamma$-glycidyloxypropyltrimethoxysilane is designed as a bridge to combine DOPO and EG. Phosphorus and silicon also have been used to polymers flame retardant. ${ }^{22-25}$ The $\mathrm{Si}-\mathrm{OH}$ groups produced from siloxane by hydroxylation can react with the hydroxyl groups of $\mathrm{EG}$ to form $\mathrm{Si}-\mathrm{O}$ bonds. The $\mathrm{P}-\mathrm{H}$ groups of DOPO can react with the epoxides of silane coupling agent to form $\mathrm{C}-\mathrm{P}-\mathrm{O}$ bonds. ${ }^{26-28}$ Herein, we propose a novel resistance mode that can effectively suppresses these problems by grafting DOPO molecular onto the EG using silane coupling agent. The surface modification has been applied to the inorganic to increase the compatibility between the filler and the polymer matrix.

In this work, a novel organic-inorganic interfacial intumescent flame retardant mode (MEG) is proposed by using grafting process containing phosphorous and applied to the EG flame retardant PP composite systems which exhibit excellent flame retardant efficiency. In this mode, the residue char is designed to increase with EG rather than independently produced from the bulk polymer as in the conventional mode. The structure of grafted EG is characterized by Fourier transform infrared (FTIR) and scanning electron microscopy (SEM). The flammability and mechanical properties of PP/MEG, PP/EG, PP/EG/DOPO composites are investigated systematically by thermogravimetry analysis (TGA), limiting oxygen index (LOI), vertical burning test (UL-94), tensile and impact test. X-ray photoelectron spectroscopy is used to explore the char residues of the PP composites.

\section{Experimental}

\subsection{Raw materials}

Polypropylene (PP) in this work was a commercial polymer PPB4808, purchased from Yanshan Petrochemical, China. Its melt flow index (MFI) was $10 \mathrm{~g} / 10 \mathrm{~min}$. Expandable graphite (EG) with particle size of $270 \mu \mathrm{m}$ was provided by Qingdao Kangboer Graphite Company. Phosphorus-containing flame retardant, 9,10-dihydro-9-oxa-10-phosphaphenanthrene-10oxide (DOPO) was obtained from Shengshida Tech \& Trade Co., Ltd., China. The $\gamma$-glycidyloxypropyltrimethoxysilane (silane coupling agent) was purchased from Chengdu Chenbang Chemical Co., Ltd., China. Ethanol and ethylic acid was obtained from Chengdu Kelon Co Ltd., China.

\subsection{Preparation of grafted expandable graphite (MEG)}

Modification of EG particles was performed according to the following steps. All materials were dried for $6 \mathrm{~h}$ to eliminate possible absorbed water on the surface of the particles. A calculated amount of DOPO and silane coupling agent were mixed in the three-necked flask and heated for $4 \mathrm{~h}$ at $160^{\circ} \mathrm{C}$ to obtain the DOPO-silane coupling agent. Then a mixed solution A was prepared with moderate amount of deionized water and $\mathrm{EG}$, and the $\mathrm{pH}$ was adjusted to 4 by adding ethylic acid. Then solution B which composed of DOPO-silane coupling agent and ethanol was added in the solution A and stirred for $4 \mathrm{~h}$ at $60^{\circ} \mathrm{C}$. Finally, the obtained mixed solution was repeatedly washed with ethanol aqueous solution to remove the excess reactants from the surface. The grafted EG product was called MEG. Schemes 1 and 2 illustrate the grafted synthesis of MEG intumescent flame retardants.

\subsection{Preparation of the composites}

PP pellets, EGs (MEG or EG), and DOPO (only for bulk mode formulation) were premixed in a mixer and then the mixture was extruded in a twin-screw extruder (TSE-20A1600-4-40, made in Nanjing, China) with a rotation rate of $150 \mathrm{rpm}$. The temperatures from hopper to die were 170, 180, 190, 205, 210, 210 , and $205{ }^{\circ} \mathrm{C}$ respectively. The extruded granulates were cooled in a water bath and cut into pellets, then dried in drier at $60{ }^{\circ} \mathrm{C}$ for $6 \mathrm{~h}$. The dried granulates were injected into standard test bars at 200,210 , and $205{ }^{\circ} \mathrm{C}$ from hopper to die in an injection molding machine (EM80-V, Chen De Plastics Machinery).

In addition, there is about $200 \mathrm{~g}$ EG used for grafting in this experiment and $216 \mathrm{~g}$ product obtains finally. Based on the increased mass of product, a $7.4 \%$ grafting ratio for DOPO on the surface of EG is calculated. Therefore, the DOPO/EG (2.22/ $30)=7.4 \%$ in the PP/EG/DOPO composites is reasonable. The formulations of the flame-retardant $\mathrm{PP}$ composites were presented in Table 1.

\subsection{Measurements and characterization}

Fourier transform infrared spectra (FTIR) of EG, MEG and DOPO were recorded on a Nicolet 560 spectrophotometer. The powders of materials were mixed with $\mathrm{KBr}$ powders, and then the mixture was compressed into plates for FTIR spectra analysis.

The LOI values were surveyed using a JF-4 type instrument (manufactured by Jiangning Analysis Instrument Factory, Nanjing China) on sheets $120 \times 6.5 \times 3 \mathrm{~mm}^{3}$ according to the standard oxygen index rest (ASTM D 2863-77).

The Underwriters Laboratories-94 (UL-94) vertical burning test was carried out on a CZF-1 type instrument (Nanjing Jiangning Analytical Instrument Factory, China), with the bar dimensions of $127 \times 12.7 \times 2.7 \mathrm{~mm}^{3}$ according to ASTM D635-77.

Thermal gravimetric analysis (TGA) was performed on a NETZSCH TG 209F1 thermogravimetric analyzer at a heating rate of $10{ }^{\circ} \mathrm{C} \min ^{-1}$ under nitrogen with a flow rate of $60 \mathrm{~mL}$ 


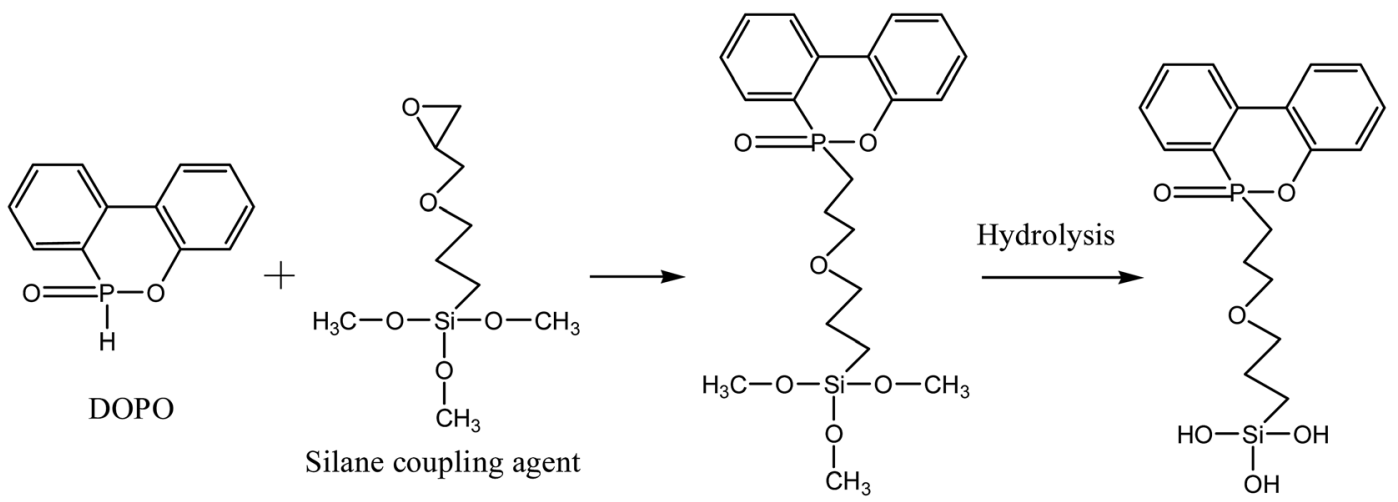

DOPO-Silane coupling agent

Scheme 1 Reaction scheme of DOPO and silane coupling agent.
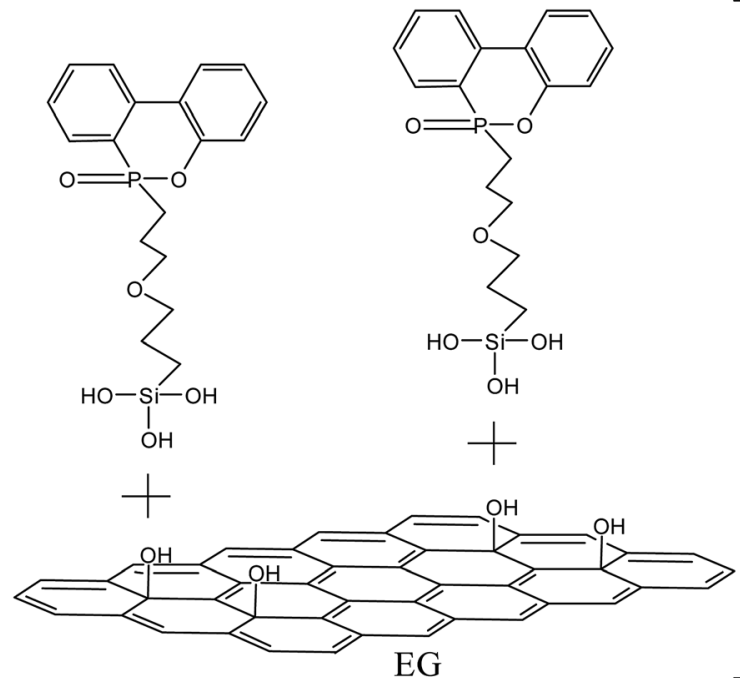

EG
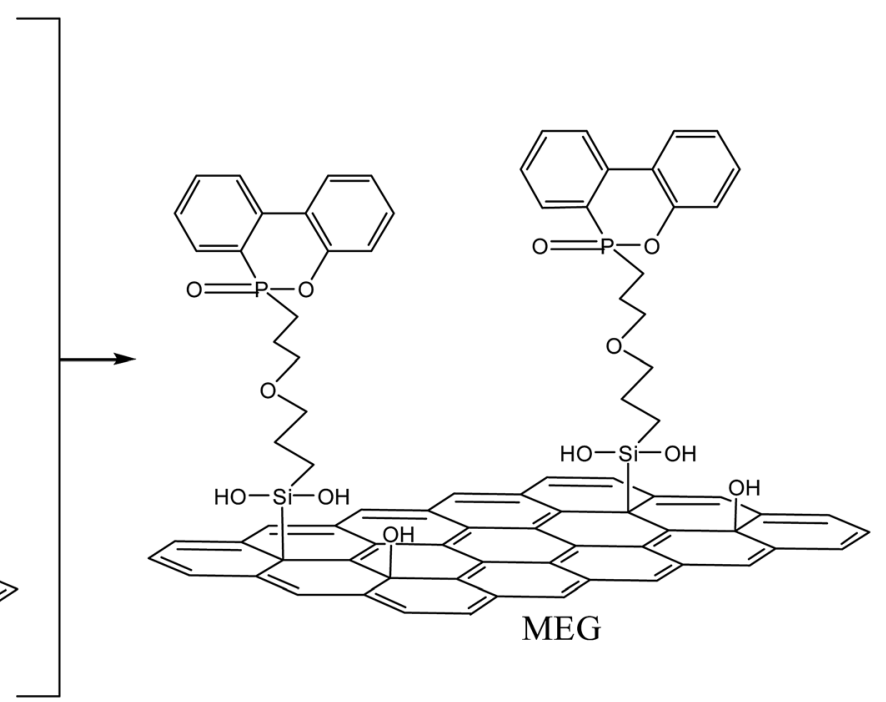

Scheme 2 Reaction schemes of DOPO-silane coupling agent and EG.

$\min ^{-1}$ and the scan range was from 30 to $700{ }^{\circ} \mathrm{C}$. About $8-10 \mathrm{mg}$ of the sample was used in this test.

The surface morphologies of the EG, MEG, burned EG and burned MEG were observed on a scanning electron microscope (SEM) (Model JSM-7500F, Japan) with a conductive gold coating and with an acceleration voltage of $5.0 \mathrm{kV}$.

X-ray photoelectron spectroscopy (XPS) of PP/EG30 and PP/ MEG30 were recorded to determine the elements in the char residue on a XSAM 800 machine.

Table 1 Formulations of pure PP and its flame-retardant composites

\begin{tabular}{lccll}
\hline Samples & PP $(w t \%)$ & MEG (wt $\%)$ & EG (wt $\%)$ & DOPO (wt $\%)$ \\
\hline PP & 100 & 0 & 0 & 0 \\
PP/MEG10 & 90 & 10 & 0 & 0 \\
PP/MEG20 & 80 & 20 & 0 & 0 \\
PP/MEG30 & 70 & 30 & 0 & 0 \\
PP/EG30 & 70 & 0 & 30 & 0 \\
PP/EG/DOPO & 70 & 0 & 27.78 & 2.22
\end{tabular}

The tensile strength of composites was measured at ambient temperature using a tensile tester AGS-J (Autograph SHIMADZU) according to GB 1040-92 (crosshead speed $100 \mathrm{~mm}$ $\left.\min ^{-1}\right)$. The Notched Izod impact tests were measured at ambient temperature on a pendulum impact tester (Model JBS300B; Shandong Drick Instruments, China) according to the ASTM D3420 standard. The results were the average values of at least five specimens.

\section{Results and discussion}

\subsection{The synthesis reaction and characterization of MEG}

The mechanism of grafting synthesis for MEG are illustrated in Schemes 1 and 2, which contains two steps. One is the $\mathrm{P}-\mathrm{H}$ groups of DOPO can react with the epoxides of silane coupling agent to form $\mathrm{C}-\mathrm{P}-\mathrm{O}$ bonds and the hydrolysis reaction of DOPO-silane coupling agent, another is grafting DOPO-silane coupling agent on the surface of EG. The Si-OH groups produced from siloxane by hydroxylation can react with the hydroxyl groups of EG to form $\mathrm{Si}-\mathrm{O}$ bonds. Therefore, the 
grafting reaction of DOPO onto the surface of EG is easy to be successfully realized.

Fig. 1 shows the FTIR spectra of DOPO, EG and MEG. The characteristic bands of EG and MEG at 1637, 2854 and $2923 \mathrm{~cm}^{-1}$ are attributed to the $\mathrm{C}=\mathrm{C}$ stretching vibrations and $\mathrm{C}-\mathrm{H}$ stretching vibrations in the aliphatic hydrocarbons, respectively. In the spectrum of EG, the strong peaks at 3432 and $1128 \mathrm{~cm}^{-1}$ are assigned to the stretching vibrations of $-\mathrm{OH}$ and $\mathrm{C}-\mathrm{O}$ groups, respectively. This indicates that EG has $-\mathrm{OH}$ groups that provide the ability to synthesize the product of hydrolysis reaction of DOPO and silane coupling agent. In the DOPO's spectrum, the band at $2437 \mathrm{~cm}^{-1}$ is attributed to $\mathrm{P}-\mathrm{H}$ stretching. After grafting onto EG, this peak is disappeared, and a new peak at $754 \mathrm{~cm}^{-1}$ attributed to the $\mathrm{P}-\mathrm{C}$ stretching vibration is appeared which suggests the occurrence of the reaction between $\mathrm{P}-\mathrm{H}$ and epoxide groups. That of MEG has another new absorption peak at 1581 $\mathrm{cm}^{-1}$ compared with the spectrum of EG, attributing to the benzene ring vibration of DOPO. This can confirm that DOPO is successfully grafted onto the surface of EG. Additionally, the $3432 \mathrm{~cm}^{-1}$ of MEG shows a relatively reduction in the intensity, which confirms the reaction between DOPO and EG. Assignments of the peaks in FTIR spectrum are presented in Table 2.

SEM analysis is used to investigate the surface morphology to confirm the formation of MEG in Fig. 2. The surface of EG is very smooth and the graphite sheet layer is clearly observed in Fig. 2a. As can been seen, the rough MEG surface seen in Fig. 2b indicates the continuous covering on the surface. This result confirms the grafting reaction is happened. Because of DOPO and silane coupling agent are easily dissolved in ethanol aqueous solution, so the excess reactants can easily be washed out by enough ethanol aqueous solution.

The TGA curves of EG and MEG in $\mathrm{N}_{2}$ atmosphere are presented in Fig. 3. Correspondingly, the temperatures, at which the relative mass loss is $5 \%\left(T_{5 \%}\right), 30 \%\left(T_{30 \%}\right)$ and $50 \%\left(T_{50 \%}\right)$, respectively, are obtained from TGA curves and listed in Table 3.

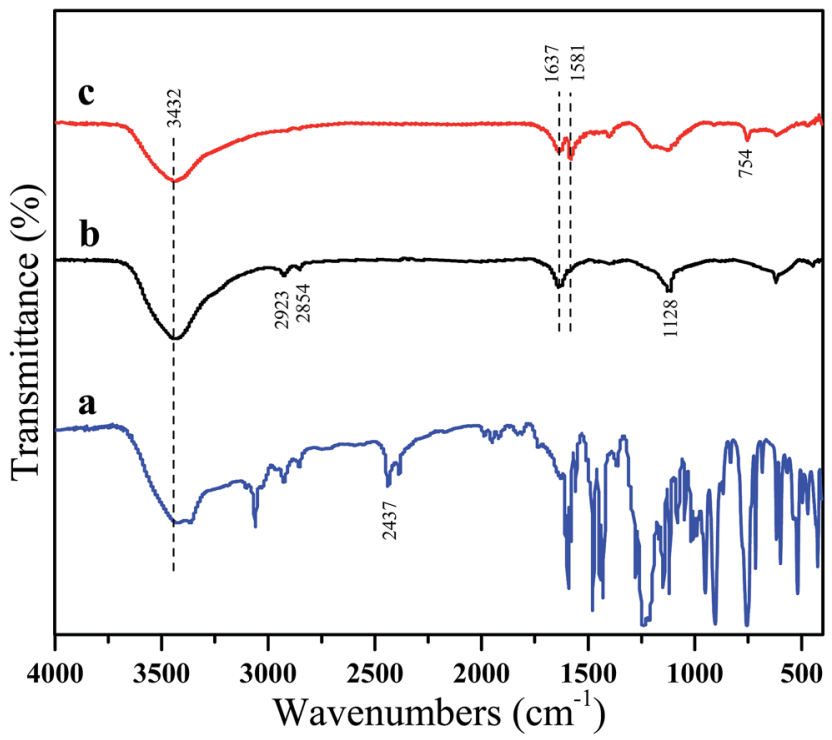

Fig. 1 FTIR spectra of (a) DOPO, (b) EG and (c) MEG.
Table 2 Assignments of the peaks in FTIR spectra shown in Fig. 1

\begin{tabular}{ll}
\hline Wavenumbers $\left(\mathrm{cm}^{-1}\right)$ & Assignment \\
\hline 3432 & Stretching vibration of $\mathrm{O}-\mathrm{H}$ groups \\
2923,2854 & C-H stretching vibration in $-\mathrm{CH}_{3}$ or $-\mathrm{CH}_{2}-$ \\
2437 & Stretching vibration of $\mathrm{P}-\mathrm{H}$ bond \\
1637 & Stretching vibration of $\mathrm{C}=\mathrm{C}$ bond \\
1581 & Benzene ring \\
754 & Stretching vibration of $\mathrm{P}-\mathrm{C}$ bond
\end{tabular}
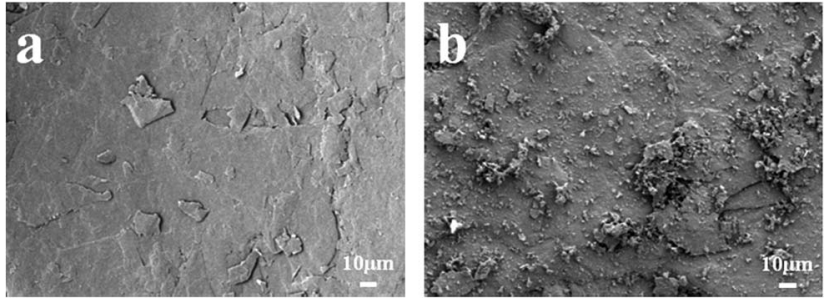

Fig. 2 The surface morphology of (a) EG and (b) MEG.

The $T_{5 \%}$ and $T_{30 \%}$ of EG are $222.2{ }^{\circ} \mathrm{C}$ and $266.8{ }^{\circ} \mathrm{C}$ respectively. However, the MEG exhibits a lower thermal stability at temperature ranging from $150{ }^{\circ} \mathrm{C}$ to $300{ }^{\circ} \mathrm{C}$ due to the low thermal stability of DOPO and silane coupling agent which will decompose to phosphate and $\mathrm{SiO}_{2}$, but a higher thermal stability at temperature above $300{ }^{\circ} \mathrm{C}$ compared with the EG. The charred residue of MEG is $55.6 \%$ at $600{ }^{\circ} \mathrm{C}$ and is much higher than that of EG. It is the thermal decomposition of DOPO that promotes EG to form a compact char layer under high temperature. Therefore, the MEG achieves better thermal stability performance than EG at high temperature.

\subsection{The flame-retardant performances of the composites}

Limiting oxygen index (LOI) and UL-94 vertical burning tests have been widely used to evaluate the flammability of polymers

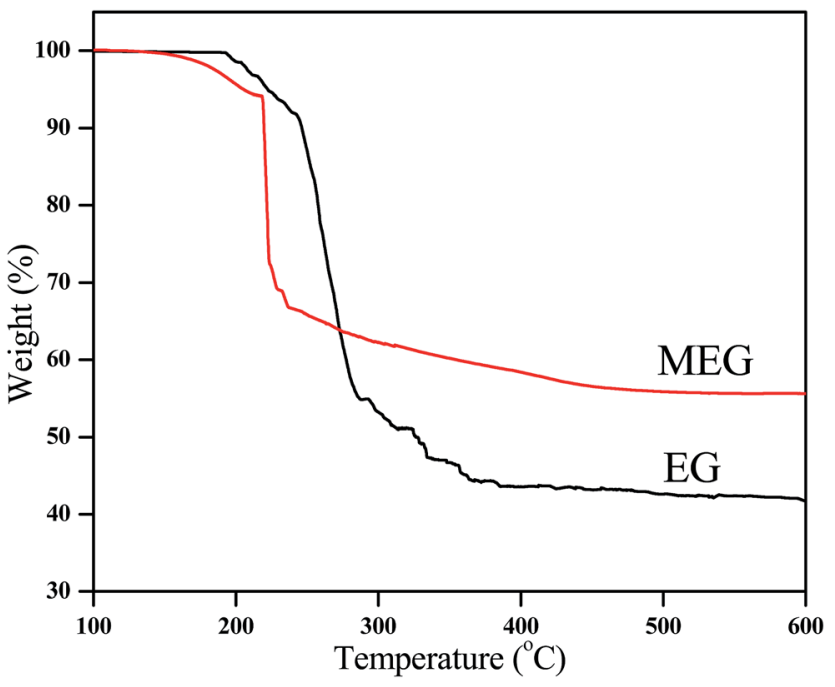

Fig. 3 TGA curves of EG and MEG in $\mathrm{N}_{2}$ atmosphere. 
Table 3 TGA data of PP and its flame-retardant composites ${ }^{a}$

\begin{tabular}{llllll}
\hline Samples & $T_{5 \%}\left({ }^{\circ} \mathrm{C}\right)$ & $T_{30 \%}\left({ }^{\circ} \mathrm{C}\right)$ & $T_{50 \%}\left({ }^{\circ} \mathrm{C}\right)$ & $T_{\mathrm{p}}\left({ }^{\circ} \mathrm{C}\right)$ & $\begin{array}{l}\text { Residues at } \\
600{ }^{\circ} \mathrm{C}(\mathrm{wt} \%)\end{array}$ \\
\hline EG & 222.2 & 266.8 & - & & 41.8 \\
MEG & 204.9 & 227.6 & - & & 55.6 \\
PP & 371.1 & 428.9 & 444.0 & 454.2 & 0.3 \\
PP/MEG30 & 338.4 & 433.7 & 457.2 & 464.7 & 25.8 \\
PP/EG30 & 367.4 & 465.2 & 475.9 & 476.6 & 24.9 \\
PP/EG/DOPO & 356.0 & 454.4 & 469.2 & 472.4 & 24.5
\end{tabular}

${ }^{a} T_{5 \%}, T_{30 \%}$, and $T_{50 \%}$, onset decomposition temperature of $5 \%, 30 \%$, and $50 \%$ weight loss, respectively; $T_{\mathrm{p}}$, peak temperature of DTG.

and their composites. The flame retardant performances of PP composites filled with EG, MEG and DOPO separately are characterized and shown in Table 4. It is observed that pure PP exhibits a LOI value of $18.1 \%$ and is not classified in the UL-94 tests. This means pure PP is highly flammable. The addition of inorganic-organic intumescent flame retardants has great effect on the flammability of materials. With the addition of MEG into PP, the LOI value of PP/MEG composites increases gradually. When $10 \mathrm{wt} \%$ of MEG is added, the LOI value rises to 21.9\%, however, this sample is failed in the UL-94 test. As the content of MEG increases to $30 \mathrm{wt} \%$, the LOI value is improved to $25.3 \%$ from $18.1 \%$ for pure PP and the satisfied flame retardant property (UL-94 V-0) is obtained.

Unfortunately, EG and EG/DOPO have slight effects on the LOI value and UL-94 rating. As listed in Table 4 , the LOI values of PP/EG30 and PP/EG/DOPO are only 23.2 and $24.2 \%$, respectively. In addition, PP/EG30 fails in the UL-94 test, however, PP/ EG/DOPO only achieves the UL-94 V-1 rating. The flammability is a little better than the PP/EG30, showing that DOPO and EG have a synergistic effect in the flame-retardant PP, but cannot improve the flame retardancy notably. Although EG is known to be an efficient flame-retardant additive that performs both as a carbon source and as a gas source.

On the other hand, the PP/MEG30 system exhibits outstanding flame-retardant properties and the UL-94 result reaches V-0 rating. The results indicate that the inorganicorganic interfacial intumescent flame retardants play great roles in the fire resistances. It is the DOPO-silane coupling agent system that can catalyze polymer matrix to form a dense carbon layer when the MEG particles are heated and the formed compact layer can effectively block the outside heat and oxygen to protect the internal polymer matrix. However, the DOPO

Table 4 Formulations and flammability of pure PP and its flameretardant composites

\begin{tabular}{lll}
\hline Samples & UL-94 & LOI $(\%)$ \\
\hline PP & NR & 18.1 \\
PP/MEG10 & NR & 21.9 \\
PP/MEG20 & NR & 23.1 \\
PP/MEG30 & V-0 & 25.3 \\
PP/EG30 & NR & 23.2 \\
PP/EG/DOPO & V-1 & 24.2
\end{tabular}

particles in PP/EG/DOPO is randomly dispersed in EG and PP matrix. The phosphate-carbon complexes cannot achieve synergistic flame retardant effect with EG at high temperature. The surprising improvement in the flame retardancy with only $2.22 \%$ DOPO-silane coupling agent concentrated on the interface implies that the flame-retardant method extremely efficient.

The digital photographs of the burned splines and SEM morphologies of pure PP and PP composites after combustion are shown in Fig. 4 and 5, respectively. It is clearly seen that the pure PP burns sharply with dripping continuously, which is very dangerous and easy to cause "secondary damage", and little char residue is found on the surface of PP sample (Fig. 4a). Some intumescent char residues are observed covered on the surface of PP/MEG composites, and the content of char residues increase with increasing the MEG content, as shown in Fig. 4b and c. But the quantity and quality of char layers are not good

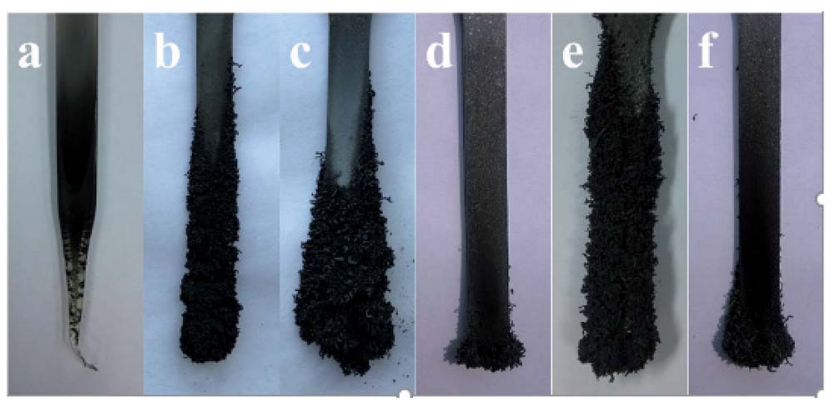

Fig. 4 Char morphologies of pure PP and the PP composites after UL94 test: (a) PP, (b) PP/MEG10, (c) PP/MEG20, (d) PP/MEG30, (e) PP/ EG30, (f) PP/EG/DOPO.
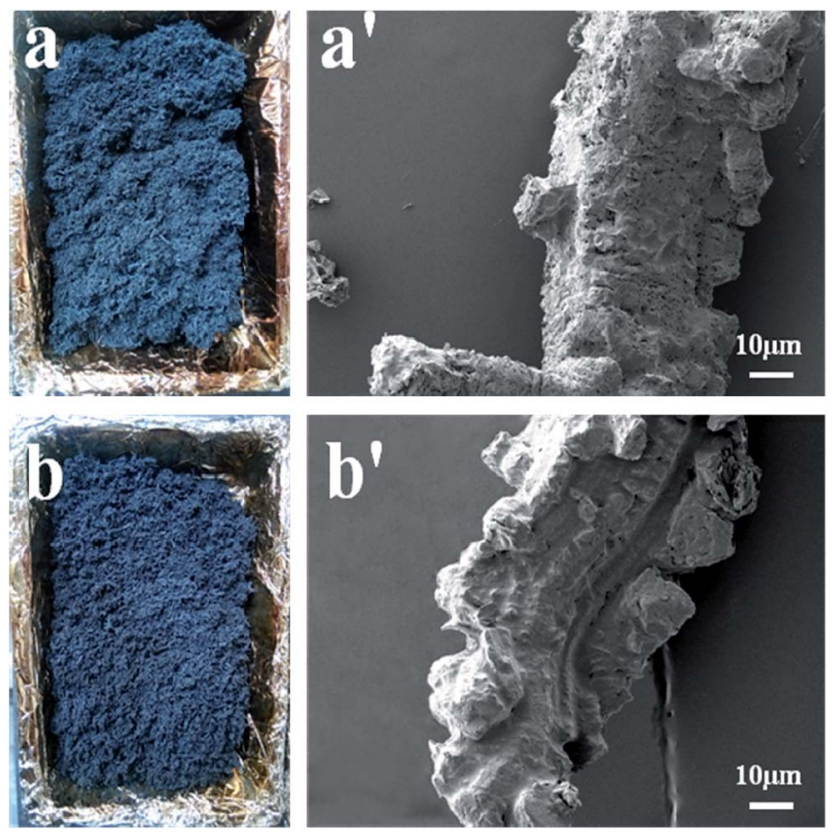

Fig. 5 The digital photographs and SEM photographs of residue surface of the flame-retardant PP composites after burning: $\left(a, a^{\prime}\right)$ PP/ EG30 and (b, b') PP/MEG30. 
enough to act as an effective protective shield for underlying polymer matrix, so the PP/MEG10 and PP/MEG20 samples cannot obtain good results in LOI and UL-94 tests. While for PP/ MEG30, an expanding and compact char layer is clearly seen. And this sample quickly extinguishes off the fire. It is observed from Fig. $5 b$ and $b^{\prime}$ that the charred residue of PP/MEG30 is more compact, continuous, and integrated. The char layer can act as an efficient and good barrier to prevent the combustible gas and heat flow from transferring into the polymer materials. The main reason is that the thick phosphate-carbon complexes and silica produced by the decomposition of DOPO and silane coupling agent can effectively agglomerate the carbon layer at high temperature. Therefore, the good synergistic effect between organic (DOPO) and inorganic (EG) intumescent flame retardants. However, compared with MEG, when the same content of EG is added into PP (Fig. 4e), it can be found that PP/ EG30 sample shows a high flame rate as the bars burned out without extinguishment after ignition. In addition, the char layer after burning is loose, discontinuous and brittle, and there are many holes on the surface of the char layer, as shown in Fig. $5 \mathrm{a}$ and $\mathrm{a}^{\prime}$. This will promote the flammable gas and heat flow transfer into underlying materials. While for PP/EG/DOPO, the morphology of charred residue shown in Fig. 4f shows that the vertical flammability is violent compared to $\mathrm{PP} / \mathrm{MEG}$ sample. This indicates that there is not enough fire retardant present to overcome the wick effect and enhance the flame retardancy remarkably.

\subsection{Thermal stability of the composites}

The TGA and DTG curves of pure PP, PP/MEG30, PP/EG30 and $\mathrm{PP} / \mathrm{EG} / \mathrm{DOPO}$ composites as a functional temperature at the heating of $10^{\circ} \mathrm{C} \mathrm{min}^{-1}$ in nitrogen are presented in Fig. 6 and 7, respectively, and the detailed data are listed in Table 3. In addition, the $T_{\mathrm{p}}$ is defined as the temperature which maximum weight loss rate occurs, corresponding to the peak temperature of DTG. It is clearly found that the thermal degradation of pure PP in $\mathrm{N}_{2}$ atmosphere is characterized by one-step with $T_{5 \%}$ and $T_{\mathrm{p}}$ at $371.1^{\circ} \mathrm{C}$ and $454.2{ }^{\circ} \mathrm{C}$, respectively. And the resulting charred residue at $600{ }^{\circ} \mathrm{C}$ is about $0.3 \mathrm{wt} \%$.

While for PP/MEG30, PP/EG30 and PP/EG/DOPO composites, the two decomposition steps of weight loss are exhibited: the first step takes place from around 220 to $380^{\circ} \mathrm{C}$; the second one, from 380 to $500{ }^{\circ} \mathrm{C}$, may be attributed to the degradation of residual materials. The flame-retardant PP composites present a lower weight loss rate and higher charred residues at $600{ }^{\circ} \mathrm{C}$ than pure PP. Compared with pure PP, it is observed that the $T_{5 \%}$ of PP/MEG30, PP/EG30 and PP/EG/DOPO are reduced by $32.7^{\circ} \mathrm{C}, 3.7^{\circ} \mathrm{C}$ and $15.1^{\circ} \mathrm{C}$. respectively. This is attributed to the thermal stability of DOPO and silane coupling agent is lower than EG, and the thermal stability of EG is lower than PP. PP/ MEG30 contains DOPO, silane coupling agent and EG, so it has the lowest $T_{5 \%}$ temperature. PP/EG30 contains only EG, so it has the highest $T_{5 \%}$ temperature. However, PP/MEG30 exhibits an enhanced thermal stability at temperature ranging from 400 to $600{ }^{\circ} \mathrm{C}$. PP/MEG30 has the highest charred residue which is $25.8 \mathrm{wt} \%$ at $600{ }^{\circ} \mathrm{C}$ compared to $\mathrm{PP} / \mathrm{EG}$ and PP/EG/DOPO. The

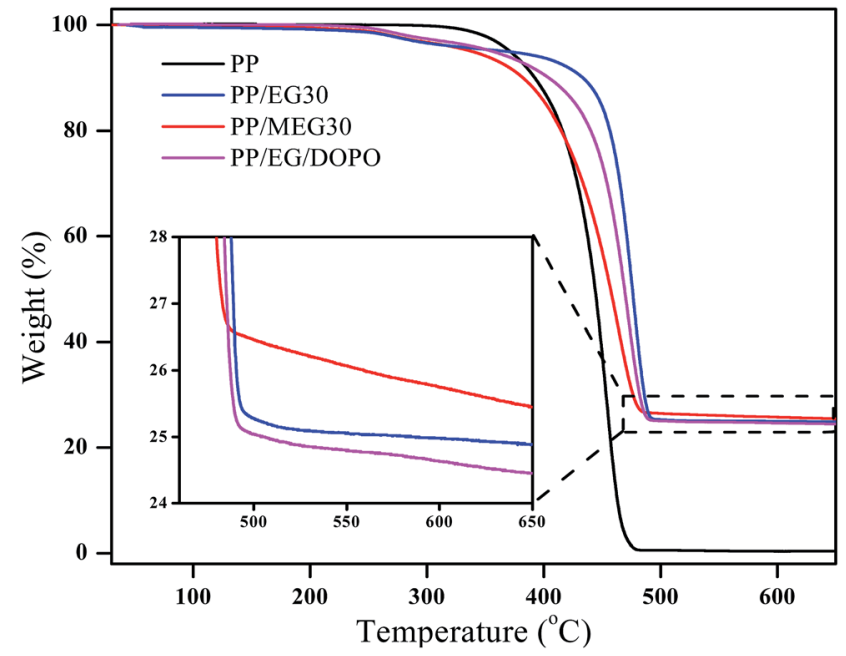

Fig. 6 TGA curves of PP, PP/EG30, PP/MEG30, and PP/EG/DOPO composites in $\mathrm{N}_{2}$ atmosphere.

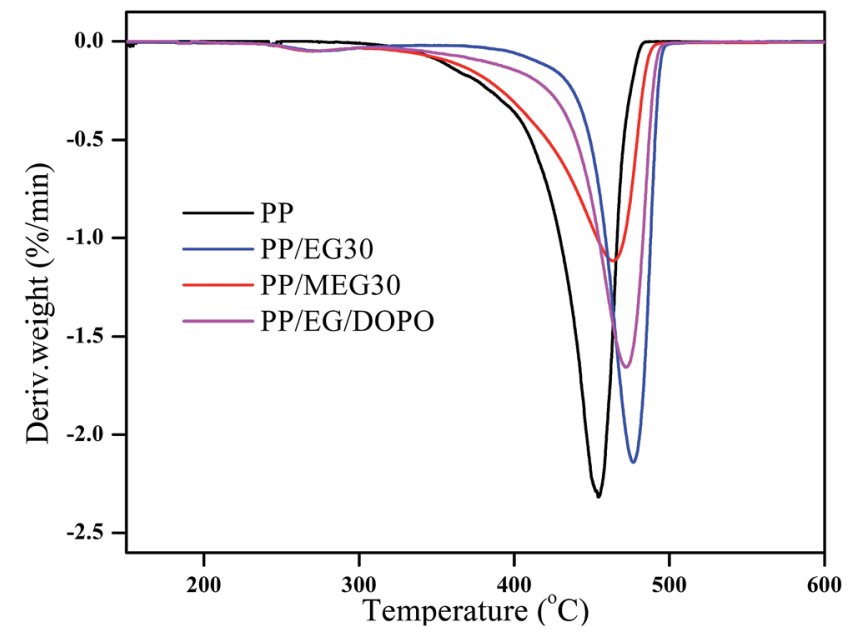

Fig. 7 DTG curves of PP, PP/EG30, PP/MEG30, and PP/EG/DOPO composites in $\mathrm{N}_{2}$ atmosphere.

higher charred residue produced, the higher barrier properties of heat and gas transfer between PP matrix and combustion zone obtained.

The participation of MEG improves the charred residue remarkably and has an obvious effect on the thermal degradation behaviors of PP composites. The TGA curves of PP composites suggest a two-stage decomposition process. In the first step, it is seen from Fig. 6 that the initial decomposition temperature of the PP composites is lower than that of pure PP due to the low thermal stability particles of DOPO and silane coupling agent which decomposes to form $\mathrm{SiO}_{2}$ and viscous phosphate-carbon complexes. At second step, with increasing temperatures, the phosphate-carbon complexes begin to dehydrate the polymer matrix and the agglomerate carbon layer to form a physical barrier layer. Then the decomposition of PP matrix becomes relatively slower due to the continuous and dense carbon layer. According to the DTG curves shown in 
Fig. 7, it can be clearly seen that the temperature of the maximum decomposition rate of PP/MEG30 is the lowest. These results indicate that the addition of MEG has less influence on initial decomposition temperature, but greater influence on the thermal stabilities of PP composites at high temperature.

\subsection{Thermo-oxidative degradation of the composites}

Dynamic FTIR is employed to evaluate the solid pyrolysis products of PP composites. The FTIR spectra of PP/EG30 and PP/MEG30 with increasing the pyrolysis temperatures are shown in Fig. 8 and 9, respectively, and the assignments of FTIR spectra are collected in Table 5. It is obviously seen from Fig. 8 that the peaks at 2960,2920, 2840, 1640, 1460, 1380 and 997 $\mathrm{cm}^{-1}$, assigning to the $\mathrm{CH}_{2}$ and $\mathrm{CH}_{3}$ vibration and the $\mathrm{C}-\mathrm{C}$ stretching vibration of aromatic ring, are the characteristic absorptions of pure $\mathrm{PP} .{ }^{29}$ The band at $3440 \mathrm{~cm}^{-1}$ decreased at the temperature of $350{ }^{\circ} \mathrm{C}$, and this can be explained by the release of water. The relative intensities of other characteristic peaks do not change below $350{ }^{\circ} \mathrm{C}$. While the temperature rises to $400{ }^{\circ} \mathrm{C}$, it's found that the absorption peaks at 2960, 2920, 2840, 1640, 1460, 1380 and $997 \mathrm{~cm}^{-1}$ disappear, indicating that the main decomposition happens at this stage. This is consistent with the TGA results.

While for PP/MEG30, the peaks at 2960, 2920, 2840, 1640, 1460, 1380 and $997 \mathrm{~cm}^{-1}$ are the characteristic absorptions of PP, as shown in Fig. 9. The FTIR spectra show very similar features compared with that of PP/EG30. When the temperature rises to $350{ }^{\circ} \mathrm{C}$, it is found that the intensities of most of peaks decrease sharply, indicating that the main decomposition of PP/ MEG30 happens at this stage. The presence of MEG catalyzes the degradation of PP matrix, which corresponds well with TGA results. When the temperature is over $350{ }^{\circ} \mathrm{C}$, two peaks at 1260 and $1120 \mathrm{~cm}^{-1}$ appear, while those are not visible in the FTIR spectra of PP/EG30. The peaks can be ascribed to the stretching vibration of $\mathrm{P}=\mathrm{O}$ and $\mathrm{P}-\mathrm{O}-\mathrm{P}$ in phosphate-carbon complexes. ${ }^{30}$

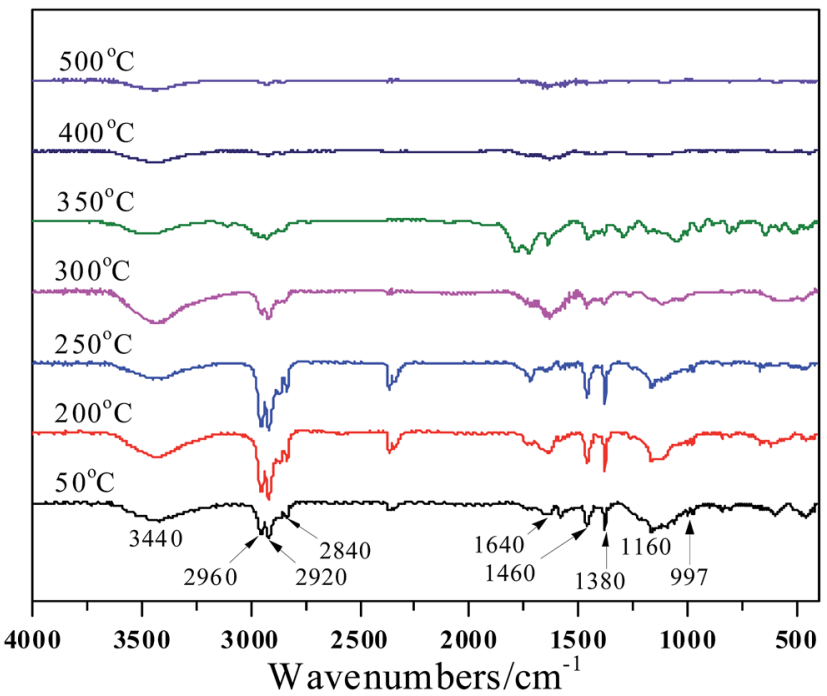

Fig. 8 The dynamic FTIR spectra at different pyrolysis temperatures of PP/EG30.

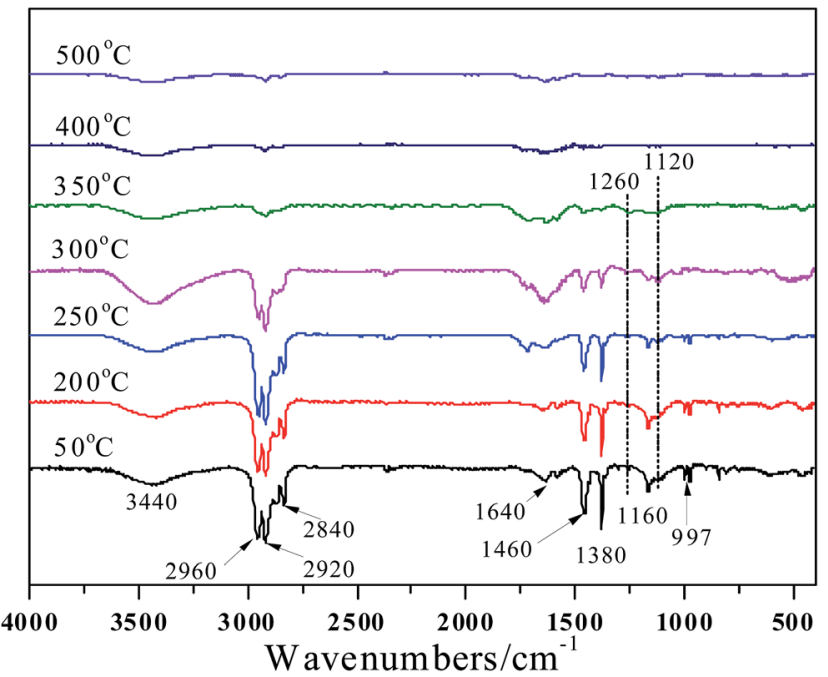

Fig. 9 The dynamic FTIR spectra at different pyrolysis temperatures of PP/MEG30.

Table 5 Assignment of FTIR spectra of the PP/EG30 and PP/MEG30 samples

\begin{tabular}{ll}
\hline Wavenumbers $\left(\mathrm{cm}^{-1}\right)$ & Assignment \\
\hline 3440 & Stretching vibration of $\mathrm{O}-\mathrm{H}$ groups \\
$2960,2920,2840$ & C-H stretching vibration in $-\mathrm{CH}_{3}$ or $-\mathrm{CH}_{2}-$ \\
1640 & C-C stretching vibration of aromatic ring \\
1460 & Scissor vibration of $-\mathrm{CH}_{2}$ \\
1380 & Symmetric vibration of $-\mathrm{CH}_{3}$ \\
1260 & Stretching vibration of $\mathrm{P}=\mathrm{O}$ bond \\
1160 & C-O stretching vibration \\
1120 & Stretching vibration of $-\mathrm{P}-\mathrm{O}-\mathrm{P}-\mathrm{O}$ \\
997 & Vibration of $\mathrm{CH}_{2}-\mathrm{CH}(\mathrm{CH})$
\end{tabular}

The presence of polyphosphate catalyzes the formation of the compactable char, which can delay the thermal degradation during the combustion. Therefore, the better flame-retardant performances can be achieved for PP/MEG30. At higher temperature $\left(>400^{\circ} \mathrm{C}\right)$, most of peaks are disappeared and only exist the residual char.

Aside from the qualitative analysis by FTIR, quantitative analysis is performed to determine the residual char of PP/EG30 and PP/MEG30 composites (heated in muffle furnace for $20 \mathrm{~min}$ at $600{ }^{\circ} \mathrm{C}$ ) by using XPS to measure variation of the characteristic element concentrations on the surface of charred residues. Fig. 10 and Table 6 show the XPS spectra and data for PP/EG30 and PP/MEG30 samples, respectively. For C1s spectrum of PP/ EG30 has four peaks: ${ }^{31,32}$ the peak at around $284.62 \mathrm{eV}$ is attributed to $\mathrm{C}-\mathrm{H}$ and $\mathrm{C}-\mathrm{C}$ in aromatic species; the peak at around $286.05 \mathrm{eV}$ is assigned to $\mathrm{C}-\mathrm{O}$ (hydroxyl group); the peak at around $287.51 \mathrm{eV}$ is corresponded to carbonyl, and the peak at around $290.29 \mathrm{eV}$ is corresponded to carboxyl groups. O1s spectrum has the peaks around 533.75 and $533.40 \mathrm{eV}$ are assign to $-\mathrm{O}-$ in $\mathrm{C}-\mathrm{O}-\mathrm{C}$ or $\mathrm{C}-\mathrm{OH}$ group, the peak at around $531.95 \mathrm{eV}$ is attributed to $\mathrm{C}=\mathrm{O}$. In addition, for the PP/MEG30 sample, O1s spectrum has another peak around $532.70 \mathrm{eV}$. It is reported that 

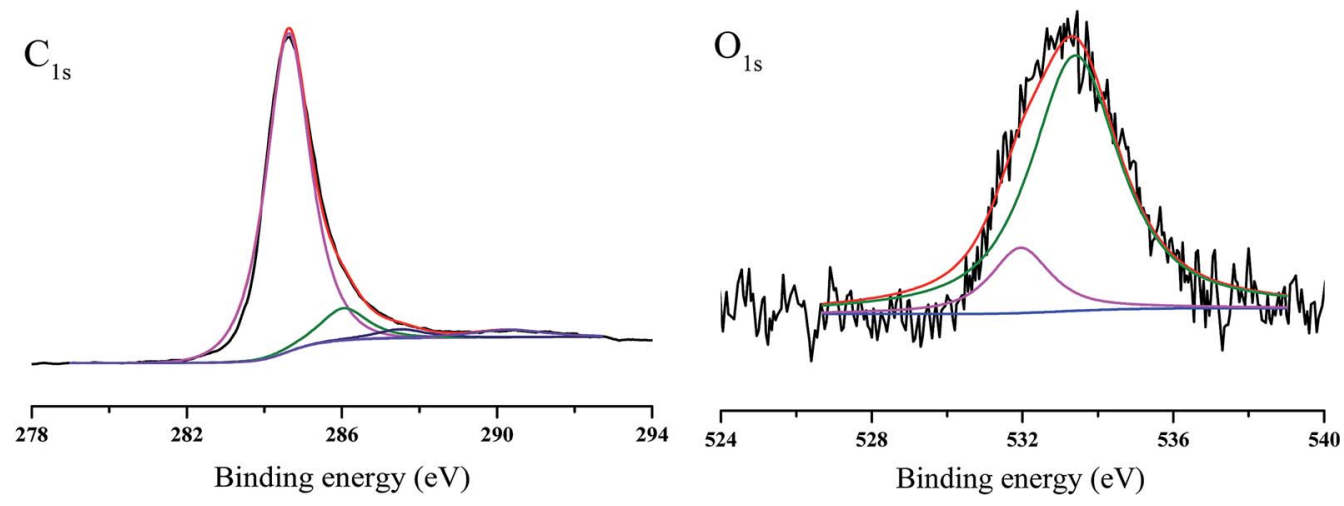

(a)
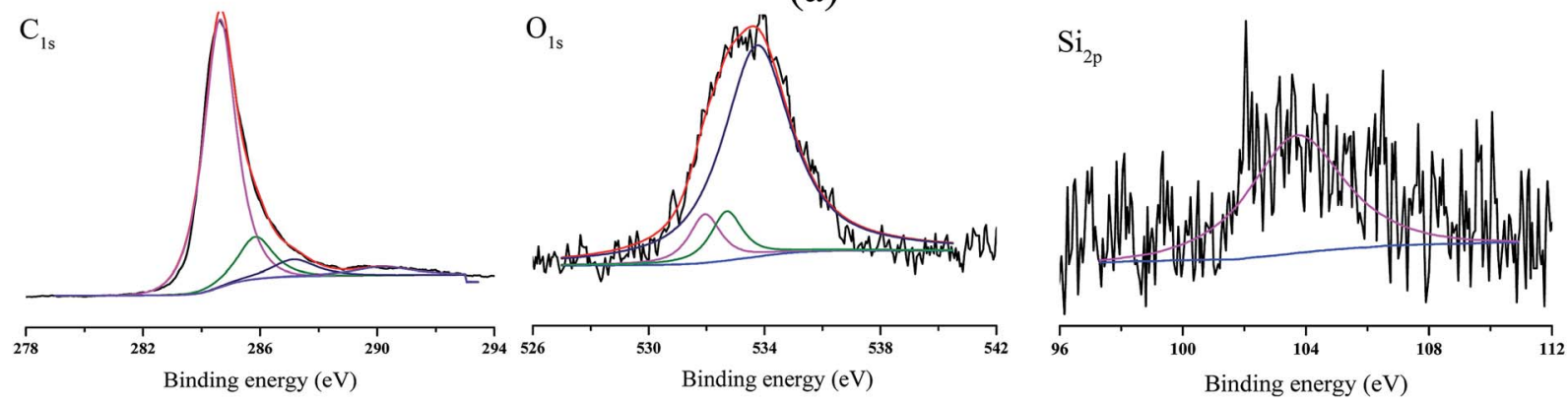

(b)
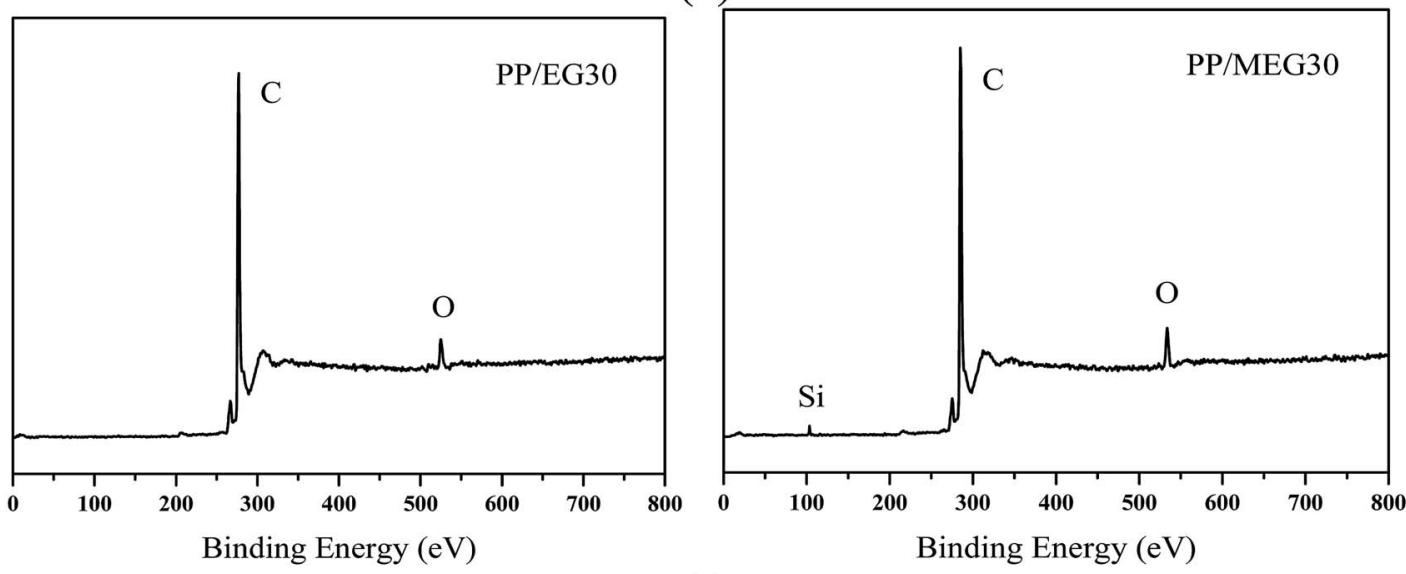

(c)

Fig. 10 XPS analysis of PP/EG30 and PP/MEG30: (a) $\mathrm{C}_{1 \mathrm{~s}}, \mathrm{O}_{1 \mathrm{~s}}$ spectra of PP/EG30, (b) $\mathrm{C}_{1 \mathrm{~s}}, \mathrm{O}_{1 \mathrm{~s}}$ and $\mathrm{Si}_{2 \mathrm{p}}$ spectra of PP/MEG30, (c) wide scanning spectra of PP/EG30 and PP/MEG30.

the peak at $532.70 \mathrm{eV}$ can be attributed to the $\mathrm{Si}-\mathrm{O}$ group. For the Si spectrum, the peak at $103.71 \mathrm{eV}$ can be assign to the $\mathrm{Si}-\mathrm{O}$ group formed by decomposition products of silane coupling agent at high temperature.

It can be found from Table 6 that the addition of MEG influences the flame retardancy and the thermal degradation of the composites due to the difference in element concentrations. The atom percent of carbon in the residues char of PP/EG30 and PP/MEG30 are $96.02 \%$ and $93.96 \%$, respectively. And the atom percent of oxygen and silicon in the residues char of PP/MEG30 are higher than that in the char residues char of PP/EG30. The presence of Si element promotes the synergistic flame retardancy for organic-inorganic intumescent flame retardants in the flame-retardant PP composites. These mean that the incorporation of DOPO-silane coupling agent into PP can promote the formation of compact residues char and enhance the thermal oxidative resistance of the PP matrix.

\subsection{Flame retardant mechanism analysis}

The surface flame retardant distribution and flame resistance modes of PP/MEG30 are illustrated in Fig. 11. It can be 
Table 6 XPS results for the surface of the PP/EG30 and PP/MEG30 samples

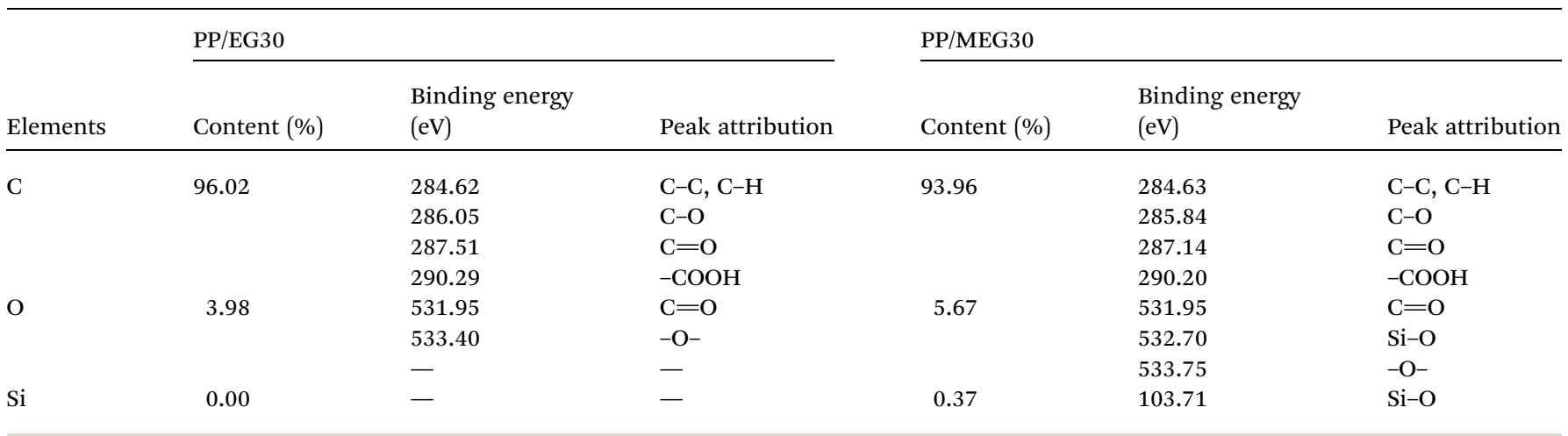

speculated that the lamella of EG, the particles of DOPO and silane coupling agent are dispersed in the PP matrix. After ignition, PP matrix releases flammable gas because of the thermal decomposition of the composites. For one thing, EG expands and forms worm-like structure, and then acts as a physical barrier for inhibiting the heat and gas transfer. For another, the thermal decomposition of DOPO-silane coupling agent produces $\mathrm{SiO}_{2}$ and polyphosphoric acid, which promotes the degradation of PP matrix to form compact char layer on the surface of PP. Accordingly, it is only if a great amount of continuous and dense chars that obtain from physical barrier of EG and catalyze charring formation of DOPO. As the organicinorganic intumescent interfacial behaviors are controlled by dynamics or thermos-dynamics, the wick effect of EG will be greatly weakened. This will improve the fire resistance of the composites.

\subsection{Mechanical properties of the composites}

Incorporation of the organic phase and inorganic phase with poor compatibility generally results in unsatisfactory interfacial combination. Compatibility always has a great influence on the mechanical performances of polymer matrix composites. Table 7 provides the mechanical properties of pure PP and flameretardant PP composites. As listed in Table 7, the tensile strength, elongation at break, and notched impact strength of pure $\mathrm{PP}$ are $31.0 \mathrm{MPa}, 446.3 \%$, and $7.2 \mathrm{~kJ} \mathrm{~m}^{-2}$, respectively.

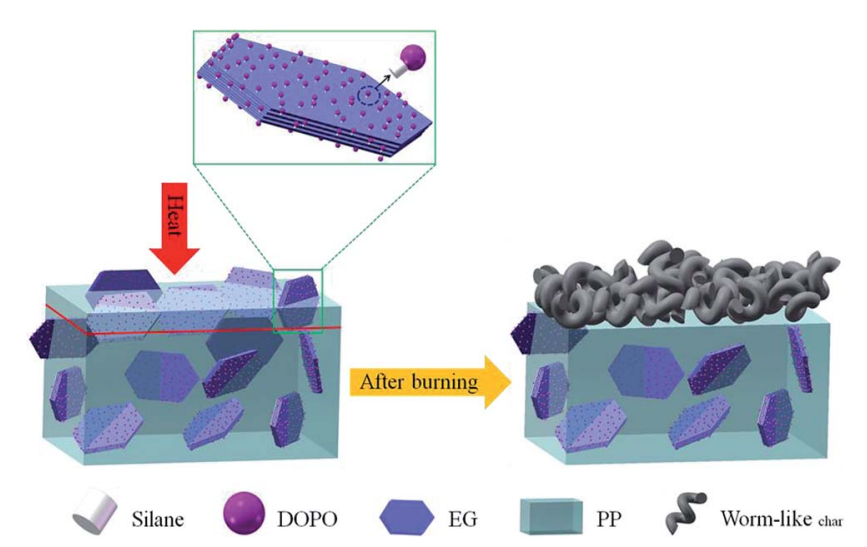

Fig. 11 The flame retardant distribution and flame resistance modes.
Compared with pure PP, the addition of inorganic particles (EG or MEG) results in the deterioration of mechanical properties for flame retardant PP composites. In addition, the mechanical performances listed in Table 7 also strongly indicate the difference in the interfacial compatibility among the systems. The tensile strength, elongation at break and impact strength of PP/MEG30 are 27.5 MPa, 9.1\%, and $5.3 \mathrm{~kJ} \mathrm{~m}^{-2}$, which increases about $7.8 \%, 18.2 \%$, and $8.2 \%$, respectively as compared to those of PP/EG. This result can be explained as the excellent compatibility between MEG and PP matrix. Obviously, the excellent mechanical performances greatly enhance the commercial value and extend the application fields for the flame retarded PP composites.

To observe the dispersion, interfacial adhesion and reinforcing mechanism of PP/EG30 and PP/MEG30 composites, the surface morphology is analyzed by SEM and the results are shown in Fig. 12. For the PP/GE30, some big holes and obvious gaps in the PP matrix can be seen between the EG and polymer

Table 7 The mechanical properties of PP and its flame-retardant composites

\begin{tabular}{llll}
\hline Samples & $\begin{array}{l}\text { Tensile } \\
\text { strength (MPa) }\end{array}$ & $\begin{array}{l}\text { Elongation at } \\
\text { break }(\%)\end{array}$ & $\begin{array}{l}\text { Notched impact } \\
\text { strength }\left(\mathrm{kJ} \mathrm{m}^{-2}\right)\end{array}$ \\
\hline PP & 31.0 & 446.3 & 7.2 \\
PP/MEG10 & 28.3 & 59.7 & 6.0 \\
PP/MEG20 & 27.8 & 25.0 & 5.9 \\
PP/MEG30 & 27.5 & 9.1 & 5.3 \\
PP/EG30 & 25.5 & 7.7 & 4.9 \\
PP/EG/DOPO & 24.6 & 6.3 & 4.6
\end{tabular}
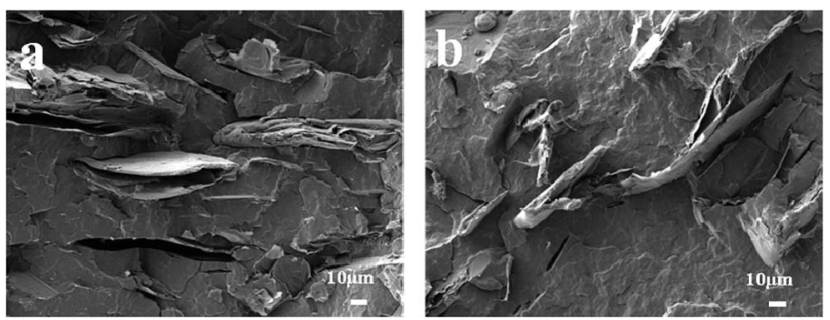

Fig. 12 The interfacial morphology of (a) PP/EG30 and (b) PP/MEG30. 
matrix, which indicates poor interfacial combinations. However, for the PP/MEG30 system, after being grafted with DOPO and silane coupling agent, the MEG has well dispersion in the PP matrix and almost no obvious interfaces are observed between MEG and the matrix. As expected, the DOPO-silane coupling agent structure can enhance the dispersion of MEG and the compatibility between the PP matrix and MEG because of the produced DOPO-silane coupling agent side chains with $-\mathrm{OH},-\mathrm{O}-,-\mathrm{P}-\mathrm{O}-$ groups.

\section{Conclusions}

A novel and efficient flame-retardant additive, MEG, which is constructed by DOPO, silane coupling agent and EG, is synthesized and characterized based on our newly proposed novel organic-inorganic intumescent interfacial flame resistance mode. The thermal behaviors and flame retardances of the flamer retarded PP composites are investigated and found to be strongly influence by the structural features of the additives used. The MEG particles showed outstanding flame-retardant efficiency on the PP/MEG30 composites because of the excellent thermal stability and high residual char yields. This observation is confirmed by the results of the LOI flammability, UL-94, TGA, the dynamic FTIR and XPS test. The wick effect of EG is efficiency eliminated due to the interfacial effect between organic and inorganic additives. Besides, the satisfactory flame retardant grade (V-0) is achieved when approximate $30 \mathrm{wt} \%$ of intumescent interfacial flame retardant MEG is incorporated into the PP matrix. Both flame-retardant MEG works in the gas phase and in the condensed phase. In addition, the organic side chains on the surface of EG improve the compatibility between MEG and the PP matrix, which results in the enhancement of the mechanical properties of the PP composites.

\section{Acknowledgements}

The authors are grateful to the National Natural Science Foundation of China (51003088), National 863 Project Foundation of China (2015AA034202), International Science and Technology Cooperation Project of Chengdu (2015-GH02-00034-HZ), High Level Innovative Talent-training Program in Guizhou Province ([2016]5667), and Dayi Science and Technology Supporting Project Foundation (2016-KC-00252-GX) for financial support of this work.

\section{References}

1 Q. Yong, W. Ping, J. Pingkai, Z. Xiaomin and Y. Haizhou, Synthesis of a novel hybrid synergistic flame retardant and its application in PP/IFR, Polym. Degrad. Stab., 2011, 96(6), 1134-1140.

2 L. Yantao, L. Bin, D. Jinfeng, J. He and G. Suliang, Synergistic effects of lanthanum oxide on a novel intumescent flame retardant polypropylene system, Polym. Degrad. Stab., 2008, 93(1), 9-16.

3 H. Daniel, W. K. Alessa, T. Ralf, D. Bettina, S. Bernhard and M. Rolf, Functionalized graphene and carbon materials as additives for melt-extruded flame retardant polypropylene, Macromol. Mater. Eng., 2013, 298(12), 1322-1334.

4 H. Minchien, L. Shuhang, L. Yufeng, W. Chungan, P. Nenwen, T. Hanmin and M. Ma Chenchi, Preparation and characterization of polypropylene graft thermal reduced graphite oxide with an improved compatibility with polypropylene-based nanocomposite, Nanoscale, 2011, 3(4), 1516-1522.

5 X. Yang, C. Man, N. Xin, C. Xiaolang, S. Zhidan, M. Yonghong, Y. Jie, Z. Zhibin, B. Xiaojin, Y. Le and C. Zining, Influences of coupling agent on thermal properties, flammability and mechanical properties of polypropylene/thermoplastic polyurethanes composites filled with expanded graphite, J. Therm. Anal. Calorim., 2014, 115(1), 689-695.

6 C. Man, T. Mengqi, M. Yonghong, C. Xiaolang, Q. Jun, H. Weidi and Z. Zhibin, Influence of polyamide 6 as a charring agent on the flame retardancy, thermal, and mechanical properties of polypropylene composites, Polym. Eng. Sci., 2015, 55(6), 1355-1360.

7 C. Man, T. Mengqi, Q. Fei, C. Xiaolang and H. Weidi, Microencapsulated ammonium polyphosphate and its application in the flame retardant polypropylene composites, J. Fire Sci., 2015, 33(5), 1-16.

8 Z. Zinan, L. Bin, Z. Ning, Y. Fengyuan and Z. Hongbin, Flame-retardant olefin block copolymer composites with novel halogen-free intumescent flame retardants based on the composition of melamine phosphate and pentaerythritol, J. Appl. Polym. Sci., 2014, 131(7), 40066.

9 D. Hongji, K. Haiquan, Z. Weiqin, J. Xu, L. Zhongming and T. Jianhua, Core-shell structure design of pulverized expandable graphite particles and their application in flame-retardant rigid polyurethane foams, Polym. Int., 2014, 63(1), 72-83.

10 C. Chiahsun, Y. Weihsin, K. Hsuchiang, K. Chenfeng and C. Chinlung, Preparation, characterization, and thermal stability of novel PMMA/expandable graphite halogen-free flame retardant composites, Polym. Compos., 2010, 31(1), 18-24.

11 L. Yun, D. Chengliang, Z. Jing, W. Junsheng, C. Li and W. Yuzhong, An efficiently halogen-free flame-retardant long-glass-fiber-reinforced polypropylene system, Polym. Degrad. Stab., 2011, 96(3), 363-370.

12 X. Yang, T. Mengqi, C. Xiaolang, C. Man, Y. Jie, M. Yonghong, S. Zhidan, Z. Zhibin and L. Jun, Effect of Red Phosphorus Masterbatch on Flame Retardancy and Thermal Stability of Polypropylene/Thermoplastic Polyurethane Blends, Polym. Polym. Compos., 2015, 23(2), 113-119.

13 Z. Xiao Guang, G. Lan Lan, Z. Wei Qin, T. Jian Hua, Y. Ling and L. Zhong Ming, Expandable Graphite-Methyl Methacrylate-Acrylic Acid Copolymer Composite Particles as a Flame Retardant of Rigid Polyurethane Foam, J. Appl. Polym. Sci., 2011, 122(2), 932-941.

14 Y. Ling, M. Xianyan, J. Xu, L. Zhongming and T. Jianhua, Synthesis and characterization of expandable graphitepoly(methyl methacrylate) composite particles and their 
application to flame retardation of rigid polyurethane foams, Polym. Degrad. Stab., 2009, 94(6), 971-979.

15 T. Mengqi, C. Man, X. Yang, C. Xiaolang, S. Zhidan and Z. Zhibin, Combustion characteristics and synergistic effects of red phosphorus masterbatch with expandable graphite in the flame retardant HDPE/EVA composites, Polym. Eng. Sci., 2015, 55(12), 2884-2892.

$16 \mathrm{M}$. Modesti and A. Lorenzetti, Improvement on fire behaviour of water blown PIR-PUR foams: use of a halogen-free flame retardant, Eur. Polym. J., 2003, 39(2), 263-268.

17 W. Zhenyu, H. Enhou and K. Wei, Influence of expandable graphite on fire resistance and water resistance of flameretardant coatings, Corros. Sci., 2007, 49(5), 2237-2253.

18 Z. Wenchao, L. Xiangmei and Y. Rongjie, Pyrolysis and fire behaviour of epoxy resin composites based on a phosphorus-containing polyhedral oligomeric silsesquioxane (DOPO-POSS), Polym. Degrad. Stab., 2011, 96(10), 1821-1832.

19 B. Schartel, U. Braun, A. I. Balabanovich, J. Artner, M. Ciesielski, M. Doring, R. M. Perez, J. K. W. Sandler and V. Altstadt, Pyrolysis and fire behaviour of epoxy systems containing a novel 9,10-dihydro-9-oxa-10phosphaphenanthrene-10-oxide-(DOPO)-based diamino hardener, Eur. Polym. J., 2008, 44(3), 704-715.

20 M. Ciesielski, A. Schaefer and M. Doering, Novel efficient DOPO-based flame-retardants for PWB relevant epoxy resins with high glass transition temperatures, Polym. Adv. Technol., 2008, 19(6), 507-515.

21 L. Wenlung, L. Lungchang, C. Chienming and L. Jianshian, Syntheses and flame retarding properties of DOPO polymers, melamine polymers, and DOPO-melamine copolymers, Polym. Adv. Technol., 2014, 25(1), 36-40.

22 C. ChinLung and C. Ri Cheng, Synthesis, characterization and properties of novel self-extinguishing organic/ inorganic epoxy nanocomposites containing nitrogen/ silicon/phosphorus via sol-gel method, Key Eng. Mater., 2007, 334-335(1-2), 665-668.

23 C. Chin Lung, C. Ri Cheng and C. Yie Chan, Thermal stability and degradation kinetics of novel organic/ inorganic epoxy hybrid containing nitrogen/silicon/ phosphorus by sol-gel method, Thermochim. Acta, 2007, 453(2), 97-104.

24 B. Perret, B. Schartel, K. Stoss, M. Ciesielski, J. Diederichs, M. Doring, J. Kramer and V. Altstadt, Novel DOPO-based flame retardant in high performance carbon fibre epoxy composites for aviation, Eur. Polym. J., 2011, 47(5), 10811089.

25 S. Gaan, L. Shuyu, H. Mispreuve, H. Perler, R. Naescher and M. Neisius, Flame retardant flexible polyurethane foams from novel DOPO-phosphonamidate additives, Polym. Degrad. Stab., 2015, 113, 180-188.

26 H. Yi, X. Yi, L. Yuan, W. Qi, Z. Zhijian and W. Zhangyu, An efficient interfacial flame-resistance mode to prepare glass fiber reinforced and flame retarded polyamide 6 with high performance, J. Mater. Chem., 2013, 1(35), 10228-10233.

27 Q. Lijun, Q. Yong, S. Nan, X. Menglan, X. Guozhi, X. Fei and C. Yajun, Pyrolysis route of a novel flame retardant constructed by phosphaphenanthrene and triazine-trione groups and its flame-retardant effect on epoxy resin, Polym. Degrad. Stab., 2014, 107, 98-105.

28 J. Vasiljevic, I. Jerman, G. Jaksa, J. Alongi, G. Malucelli, M. Zorko, B. Tomsic and B. Simoncic, Functionalization of cellulose fibres with DOPO-polysilsesquioxane flame retardant nanocoating, Cellulose, 2015, 2(3), 1893-1910.

29 W. Qiang and Q. Baojun, synergistic effect of silicotungistic acid on intumescent flame-retardant polypropylene, Polym. Degrad. Stab., 2001, 74(2), 255-261.

30 W. Xin, H. Yuan, S. Lei, X. Weiyi, L. Hongdian, L. Pin and J. Ganxin, Flame retardancy and thermal degradation mechanism of epoxy resin composites based on a DOPO substituted organophosphorus oligomer, Polymer, 2010, 51(11), 2435-2445.

31 S. Lei, H. Qingliang, H. Yuan, C. Hao and L. Lei, Study on thermal degradation and combustion behaviors of $\mathrm{PC} /$ POSS hybrids, Polym. Degrad. Stab., 2008, 93(3), 627-639.

32 W. Xin, S. Lei, Y. Hongyu, L. Hongdian and H. Yuan, Synergistic effect of graphene on antidripping and fire resistance of intumescent flame retardant poly(butylene succinate) composites, Ind. Eng. Chem. Res., 2011, 50(9), 5376-5383. 